\title{
Pay for performance: learning about quality
}

\author{
Chaim M. Bell, Wendy Levinson
}

$\infty$

$\mathrm{M}$ ost doctors feel that they provide good to aboveaverage patient care. However, Canadian physicians rarely receive feedback about their clinical performance or patient outcomes. Although both of us believe that we provide excellent patient care, we have never received any data on our clinical performance or patient outcomes compared with other physicians or benchmarks. How can we learn to improve our provision of care without objective measures of our performance?

Measurement is a key first step toward improving quality. In the last decade, there have been movements in the United States, United Kingdom and Australia to systematically measure quality-of-care indicators. Some of these programs, called pay-for-performance programs, have linked financial rewards to the provision of health care. ${ }^{1-3}$ Quality is typically assessed by evidenced-based, process-of-care measures, such as the proportion of patients with myocardial infarction who are receiving $\beta$-blocker therapy at the time of discharge from hospital or the fraction of eligible women who receive Papanicolaou smears. Process-of-care measures are generally selected because they are relatively easy to assess and theoretically relate to important patient outcomes, such as survival.

There are various pay-for-performance models (Box I). ${ }^{1,45}$ Their structure depends on several factors, including intended recipient of the reward (an individual or group) and the type of payment scheme. Performance can be measured and rewarded at the individual, group, hospital or regional level. Analysis of the care provided by groups recognizes that the quality of care depends on multiple providers; however, it is challenging to link the reward to an individual physician's efforts. Various payment schemes can be used: high-quality care can be rewarded or lowquality performance can be penalized based on quality benchmarks. Performance-related reimbursement can vary from a small bonus to a sizable proportion of overall clinical income. For example, a US Medicare project provides a $2 \%$ bonus to the highest quality hospitals, and in the United Kingdom about $25 \%$ of general practitioners' income can depend on achieving quality targets. ${ }^{2,6}$ Ontario's new primary care models include incentive payments for preventive measures, up to a maximum of $\$ 2200$ for each of childhood immunizations, influenza vaccines, fecal occult blood testing, Pap smears and mammograms.
In this issue of $C M A J$ (page 1705), Millett and colleagues ${ }^{7}$ report on their study of 2 facets of pay-for-performance incentives: whether financial incentives improve process-ofcare measures and whether financial incentives improve patient outcomes. Using a study population of patients with diabetes in 32 participating primary care practices in southwest London, England, the authors examined the impact of pay-for-performance incentives introduced in 2004 on the documentation of smoking status and on the delivery of smoking cessation advice. They reported that the proportion of patients who had their smoking status recorded increased from $90.0 \%$ in 2003 to $98.8 \%$ in 2005 and that the proportion of patients who received smoking cessation advice increased from $48.0 \%$ to $83.5 \%$ during this period. They noted that the prevalence of smoking in the study population decreased from $20.0 \%$ in 2003 to $16.2 \%$ in 2005 . Improvements were generally greatest in the groups with the poorest performance in the 2003 study period and among ethnic minorities - populations that traditionally receive lower quality care. Hence, these efforts may have helped to reduce variation in care between groups. The study by Millett and colleagues provides some evidence for the positive impact of pay-for-performance incentives on important measures of care.

These findings prompt a key question about pay-forperformance initiatives: ${ }^{9}$ Do these incentives result in improved patient outcomes or do they just lead to improved documentation and use of processes of care? For example,

Box 1: 2 pay-for-performance models

Reward based

- Can be to an individual, group, hospital or region

- Compensation given if quality targets met

- Higher fee schedule for superior performance

- Increased payment rates for demonstrated high-quality providers

Penalty based

- Can be to an individual, group, hospital or region

- Compensation withheld if quality targets not met or performance not improved

- Lower fee schedule for inferior performance 
in the study by Millet and colleagues, we don't know if the patients acted on smoking cessation advice by seeking cessation programs. Cohort studies that examine pre- and post-intervention trends cannot control for secular trends (e.g., toward decreased smoking), which makes it difficult to ascribe the observed effect to the intervention alone.

Translating these findings into a Canadian context brings challenges. First, Millett and colleagues evaluated the delivery of care in a single geographic area with a different health care delivery model. The amount of ethnic diversity in this population may be different from that in most areas of Canada, although clinicians in Canadian urban centres may see similar diversity. Second, it is difficult to discern the impact that the pay-for-performance incentive had on individual physicians because the data were aggregated across practices. Finally, the entire UK pay-for-performance program relied on a comprehensive, well-developed referral program for smoking cessation, which is not available to the same extent throughout Canada. Despite these challenges, the study by Millett and colleagues is a step in the right direction to measure and improve the processes of care for an important health issue. Their findings provide motivation to continue to study financial incentives as a tool to improve the quality of health care delivery.

Overall, pay-for-performance incentives have been criticized for a variety of reasons (Box 2). The relative lack of high-quality studies on the benefit of these incentives appears contradictory to our usually stringent evidence-based requirements in other areas, such as pharmaceutical and technology interventions. ${ }^{9}$ Some studies have found improvements in process-of-care documentation but no improvement in patient outcomes. ${ }^{4}$ Other studies have sug-

Box 2: Potential benefits and challenges

of pay-for-performance incentives

Benefits

- Demonstrate a commitment to the provision of evidencebased health care

- Will lead to improvements in quality-reporting infrastructure

- Reward high-quality health care

- Transparent process of rewards

- Can focus attention on underserved or high-risk groups

Challenges and uncertainties

- Unintended effects not well studied (e.g., distraction from nontargeted conditions)

- No consensus about optimal program strategy (must be individually tailored to local programs)

- Uncertain association between improved physician performance and patient outcomes

- Difficult to measure outcomes in complex patient populations

- May provide incentives for inappropriate patient management and treatment

- Few data on cost-effectiveness; funds and attention may be better spent elsewhere gested that the benefits observed could be achieved at less cost through other strategies. ${ }^{10}$ There is much uncertainty about how to implement pay-for-performance programs, including the selection and unit of measures, the size of incentives and how to account for patient complexity. ${ }^{5}$ Pay-forperformance incentives may result in a focus on conditions or diseases that have easily reportable and measurable processes of care. ${ }^{10}$ The desire to "go for the money" in a time-constrained clinical encounter may distract the physician from other important issues such as the patient's quality of life or counselling. By rewarding some areas but not others, payers are explicitly ascribing value to certain diseases and conditions over others.

The study by Millett and colleagues underscores the importance of reliable and timely feedback mechanisms to measure the quality of health care. Such mechanisms require the use of information technology, such as electronic medical records. In the United Kingdom, incentive payments were provided to general practitioners during the first 3 years of the program to cover additional infrastructure costs regardless of performance. ${ }^{1}$ In North America, the cost of implementing electronic record keeping has been a barrier to these programs.

Measurement of quality of care and provision of rewards for performance are not the same thing - only after measurement skills are developed can we consider incentive strategies. Canadian efforts in quality measurement should first learn to walk well before trying to run. Canadian physicians must have access to the quality information technology resources and measurement systems that other countries have been using for years to inform physicians about health care quality and clinical outcomes. Any strategies that do not include this fundamental foundation will have limited effect.

No physician chooses to provide low-quality health care, especially if an opportunity to provide better care is available. Like other Canadian physicians, we would welcome the opportunity to receive individualized feedback and suggested intervention strategies to help us better pursue excellence in patient care. Pride and professional ethos have been identified as drivers in quality improvement. ${ }^{3,9}$ We agree with rewarding quality care that improves patient outcomes. What is the best method to reward quality that in turn improves patient outcomes still remains uncertain.

\section{This article has been peer reviewed.}

Chaim Bell is with the Institute for Clinical Evaluative Sciences, Toronto, Ont. He and Wendy Levinson are with the Department of Medicine, University of Toronto and St. Michael's Hospital, and the Keenan Research Centre, Li Ka Shing Knowledge Institute, St. Michael's Hospital, Toronto, Ont.

Competing interests: None declared.

Contributors: Both authors contributed substantially to the conception and design of the manuscript, drafted the article and revised it critically for important intellectual content, and gave final approval of the version to be published.

Acknowledgements: Chaim Bell is supported by a New Investigator Award from the Canadian Institutes for Health Research. 


\section{REFERENCES}

I. Pink GH, Brown AD, Studer ML, et al. Pay-for-performance in publicly financed healthcare: some international experience and considerations for Canada. Healthc Pap 2006;6:8-26.

2. Doran T, Fullwood C, Gravelle H, et al. Pay-for-performance programs in family practices in the United Kingdom. NEngl J Med 2006;355:375-84.

3. Rosenthal MB, Frank RG, Li Z, et al. Early experience with pay-for-performance: from concept to practice. JAMA 2005;294:1788-93.

4. Petersen LA, Woodard LD, Urech T, et al. Does pay-for-performance improve the quality of health care? Ann Intern Med 2006;145:265-72.

5. Rosenthal MB, Dudley RA. Pay-for-performance: will the latest payment trend improve care? JAMA 2007;297:740-4.

6. Lindenauer PK, Remus D, Roman S, et al. Public reporting and pay for performance in hospital quality improvement. N Engl J Med 2007;356:486-96.
7. Millett C, Gray J, Saxena S, et al. Impact of a pay-for-performance incentive on support for smoking cessation and on smoking prevalence among people with diabetes. CMAJ 2007;176:1705-10.

8. Agency for Healthcare Research and Quality. National healthcare quality report, 2006. AHRQ Pub no 07-00I3. Available: www.ahrq.gov/qual/nhqro6/nhqro6.htm (accessed 2007 Apr I9).

9. Epstein AM. Pay for performance at the tipping point. NEngl J Med 2007;356:515-7.

Io. Rosenthal MB, Fernandopulle R, Song HR, et al. Paying for quality: providers' incentives for quality improvement. Health Aff (Millwood) 2004;23:127-4I.

Correspondence to: Dr. Chaim M. Bell, St. Michael's Hospital, 30 Bond St., Toronto ON M5B IW8; fax 416 864-5485; bellc@smh.toronto.on.ca

\section{Encouraging medical students to do research and write papers}

\section{Michael E. Detsky, Allan S. Detsky}

S ociety has a vested interest in supporting and promoting health care research. Physicians, among other clinical professionals, have an important role to play. In recent years, many have decried the lack of opportunities for physicians to perform research. ${ }^{1}$ Encouraging medical students and postgraduate trainees to engage in research projects is an activity that should be given high priority. ${ }^{2,3}$

In this commentary we offer the perspectives of a student who has had recent experience with publication ${ }^{4-6}$ and a senior clinician-researcher who has guided several medical students and residents through the process..$^{7-10}$ Although as a father and son we have not previously written a paper together, we have exchanged many stories about our successes and failures and those of our peers, an advantageous and ongoing learning opportunity that we both have enjoyed. We therefore offer advice for both students (summarized in Box I) and mentors (Box 2).

\section{The student's advice}

First, a commitment to do a research project must be made. Balancing medical school and a social life can be a challenge, and adding another activity will make considerable demands on your time. If you decide to do a project, acknowledge that this is something you are willing to carry through to completion, which may take years. Taking on a project that becomes more complex or demanding than one imagines is an error common among first-time researchers. If a smaller, less ambitious project presents itself, that may be a more appropriate first attempt at research.

Second, find a project in an area of interest to you. Start by considering the papers you enjoyed reading outside of the required curriculum. Do not take on a project simply because a faculty member you approached suggested it and you do not want him or her to feel offended. Think twice before saying "yes" to the first idea floated.

Next, you must seek out a supervisor. In doing so, it is imperative that you "research the researcher" before you take on a project. Asking others who have worked with the supervisor is a great option. Stay away from those who take weeks to respond to questions, review protocols or provide comments on drafts of manuscripts. Because students often feel intimidated, this situation is a difficult one. Look for supervisors

Box 1: Advice for students

- Be aware of the scope of your research project, including its length - will it take months or years to complete?

- Choose a smaller project rather than one that will be (or looks likely to become) complex and demanding

- Make a personal commitment to finish the research

- Choose an area of interest to you, irrespective of other pressures and suggestions

- Research your potential research advisor

- What is her or his track record on grants and publications with other student coauthors?

- Has he or she been responsive and supportive to previous students? If so, were the responses timely?

- Make contingency plans for things that may go wrong

- Stay in touch: communicate often with team members

- Coordinate with your teammates to guarantee a single "hot copy" or active draft of the paper, to avoid developing parallel versions

- Back up your data regularly; store a copy offsite

- If you find that research is not your "thing," investigate other means to achieve your career goals 